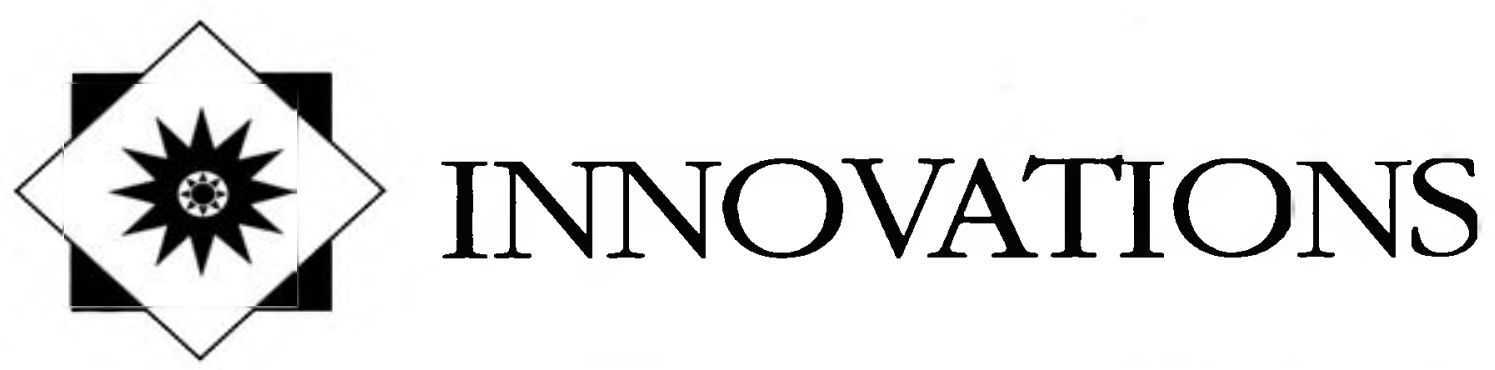

\title{
Innovation and value-added information delivery
}

\author{
By Caroline M. Coughlin
}

Director
Drew University Library

Drew University is an atypical, small, highly selective liberal arts university. Over the past five years, it has invested $\$ 3.5$ million in cutting-edge technology and installed a campus-wide voice and data system with an integrated online library system at its center. At Drew the age of remote access for all users has arrived. What makes this fact particularly interesting is that Drew University is not a large or rich university with an emphasis on science and technology; rather, it is a small university that emphasizes work in the liberal arts.

By participating in the enterprise of finding new truths in classic texts, users of the Knowledge Network at Drew are discovering that they must engage themselves in the information revolution of our time. Traditionally book-oriented, they have become quite adept at mastering the new electronic system. Given the fullness of the voice-data system Drew has installed, the university is a leader in the use of technology to support instruction and research in a liberal arts college environment.

Faculty members can coach students via electronic mail and help them find the right library resources for their research. Faculty have developed computer-based teaching approaches to mastering material as diverse as musical notation, the 1988 election, or theories of child development. Students find faculty more accessible, get better critiques of their drafts of papers, and have the luxury of looking for library resources at 2:00 a.m. or during class, whenever it is either biologically in tune with their work rhythms or necessary to address a topic under review.

All faculty and all college students are issued personal computers and have mailboxes on the electronic network. There are no categories of people (underclassmen, poorer students, non-sci- entific students, or faculty) excluded from the network. While the system is still new, it has become the normal way to do things. Ideally, the system would include all resources, texts as well as citations, but that development is still in the future.

At the same time, Drew's College of Liberal Arts is also a typical college. The College enrolls 1,500 students in 26 traditional majors and is highly selective in its admissions. Drew has a history of balancing its budget collegially and cautiously. A natural outgrowth of the caution is that a long list of campus-wide needs includes such diverse items as a new student center, endowments for faculty salaries, increasing the library's materials budget, more parking spaces, and a new chapel for the seminary. Choosing to spend a significant sum on technology ahead of other equally important areas is a clear decision to focus on innovation and value-added services.

Why was technology the chosen area for innovation? What were the Drew decision-makers trying to accomplish? What does it mean for the Drew Library? What does it mean for other academic libraries? A flashback to the Drew environment of 1982 reveals some of the answers.

\section{The Computer Initiative}

In 1983 the University researcher at Drew alerted the faculty and budget-makers to the realities of the coming decade. Maintaining a highly selective student body of a size that permitted balancing the budget would be more difficult because of the shrinking pool of potential applicants in the Northeast. Liberal arts colleges that did not distinguish themselves in significant ways from their peer institutions would lose applicants to 
better known or more competitive colleges of the same type. Choices had to be made, whether planned retrenchment, planned growth based on a less competitive student profile, or an increase in value and therefore an increase in competitiveness. Also around 1983, several high-tech universities were embarking on programs to wire their campuses and increase the availability of personal computers to their students and faculty. The Chronicle of Higher Education reported that the concept of the scholar's workstation was under development at several renowned universities, and faculty at humanities-oriented universities and colleges were following suit and trying to determine their needs for comparable workstations. Simultaneously many colleges reported heavy increases in the number of students enrolling in business and computer courses. Drew's College of Liberal Arts faculty was immune to neither trend; it added a computer science track to the mathematics major in the early 1980 s, and some faculty daydreamed about the ultimate workstation to suit their teaching and research needs.

During 1983 the College faculty discussed all of the above, especially the question of demographic projections of college-age students in the Northeast. The faculty easily agreed that Drew did not wish to plan either a program of retrenchment or a program of growth that necessitated lower aca- demic standards. The success of the new program in computer science was a stimulus to other faculty, and engendered interdisciplinary activity by faculty who crossed departmental lines to share in computer-oriented curriculum development.

By 1983 several faculty members were meeting regularly and the Computer Initiative was born. As eventually endorsed by the full faculty, the Computer Initiative had (and still has) a simplicity that is engaging: issue personal computers to all incoming freshmen and all faculty, teach both groups to incorporate use of the computer into the liberal arts curriculum, and fund the Program by a surcharge on tuition. The administration and trustees accepted the plan, primarily because it came from the faculty and was conceptually interesting and wellbudgeted, and secondarily because it appeared to offer some way of permitting the College of Liberal Arts to offer students additional value in an increasingly competitive market for students.

In the fall of 1984, the Program began, and it quickly had the desired effect on both the curriculum and the applicant pool. There was another effect as well. The process of self-identification of Drew with innovation in the technological arena had begun, and before too long some of the faculty wished to develop further applications and expand the Program.

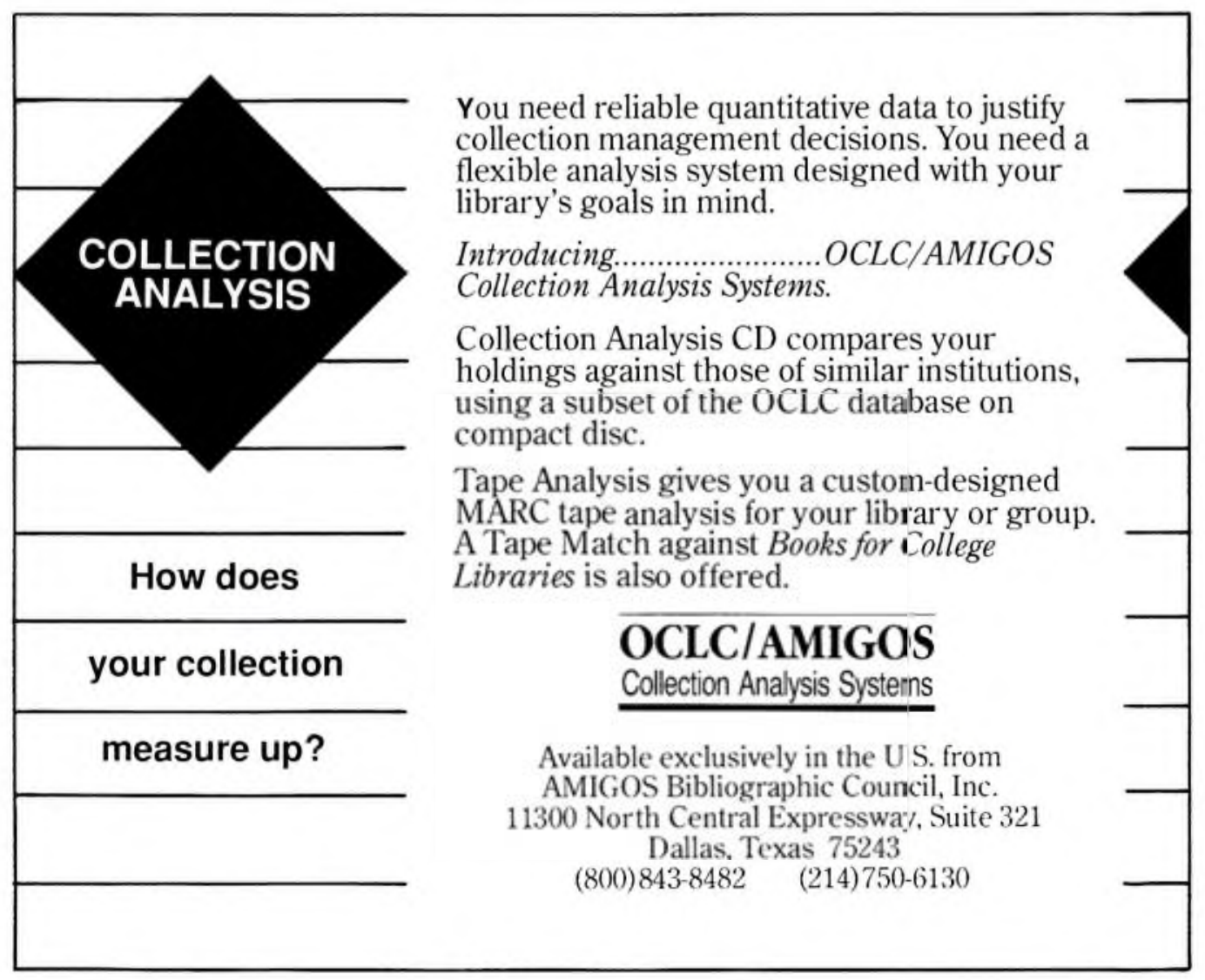




\section{The Knowledge Network}

Innovation is contagious. The goal of the Computer Initiative was expanded, and under its new name, the Knowledge Initiative, it was given a larger goal, that of installing a network to link all the personal computers on campus and adding the library's resources to the network. Tom Peters in his book, Thriving on Chaos, links innovation to value-added services and calls these intertwined concepts the basis for any future success of organizations wishing to be competitive in a modern economy. Drew began its cycle of innovation by focusing on technology-specifically the personal computer and the value it could bring to the work of faculty and students. Drew faculty and students quickly understood that the introduction of a particular machine was only part of a complete valueadded service. More important to Drew faculty, students, and administrators were the benefits that could accrue if information delivery were added to the innovation. This concept of improved information delivery became the cornerstone of all the research cost comparisons, and consensus building done between 1985 and 1989.

The need was to capture additional funding from the university to transform the Computer Initiative into the Knowledge Network. In 1985 the library's request for funding to automate the library was already three years old, and a number of grant proposals had been submitted to the logical funding sources. None of the larger requests for funding was successful, but several small grants to provide support for retrospective conversion and planning were received. Retrospective conversion became a part of the work of the library beginning in 1981, and in 1984 a full-scale planning document was created. Both activities kept library staff focused on the long-term goal of being an online library by 1989. At opportune times, librarians reminded the faculty and administration that having an automated library on the new network would be a good idea.

The quest for additional funding for a variety of campus needs led to the formation of six joint faculty-trustee task forces. Each was instructed to study the desirability of a given idea, price it, and make recommendations for the next round of capital improvements at Drew. One of the topics was the new network and library automation; other items on the list included endowments for new faculty and for compensation improvements, sports and recreation facilities, educational facilities, arts facilities, and a new student center. Each task force educated itself with the help of staff. The network/library automation task force visited Lehigh University, a networking and library automation pioneer, and also did extensive reading and developed budget estimates. When the work of these task forces was completed and campus priorities set, the installation of the network, complete with library automation, was one of the top three priorities. With this kind of affirmation of the centrality of the priority to the educational mission of Drew, the search for funding intensified. No longer was only the library administration asking for funds for library automation. Now the campus community, as represented in an influential faculty-trustee task force, was asking for library automation as part of a larger goal, a wired campus.

The fact that the campus telephone system was severely overloaded pushed the urgency of the need. In the spring of 1988 the trustees allocated funds for a new telephone system with the understanding that such a system should serve the network. Having worked together to support the work of the task force, the vice-president for technology and planning and the library director began working to spend the allocated funds wisely. In consultations with others, they decided to purchase a computer that could drive the campus voice-data system first and later support library automation when additional funds could be made available. The library allocated precious space to house the network computer and to provide technical staff with office space.

On the day of the network center's official opening, complete with ribbon-cutting ceremonies attended by trustees and the officials of companies supplying the technology, a series of walk-through demonstrations offered all visitors and trustees a peek at its capabilities. One of the twelve demonstrations was of a library's online public-access catalog, courtesy of a linkup to the College of Charleston through Data Research Associates. The trustees understood that automation in the library would be the next area to support with respect to the network.

While Drew personnel involved in the project knew how distinctive the Knowledge Initiative was and how special it made the liberal arts linkage to technology at Drew, it was difficult to explain the richness of the system without the presence of library automation on the network. Visitors to the campus were often puzzled to learn what we had done, because the Drew approach differed from that of similar institutions. Most quality liberal arts institutions had purchased integrated library systems for their campus and were now trying to find the funds to purchase and install a network and increase the number of personal computers available to students. High school seniors touring the campus with their parents or guidance counselors would ask when the library would be automated like the library is at institution $x, y$, or $z$. This situation was unacceptable to several Drew trustees who had served on the network/library automation task force. They wanted to see the knowl- 
edge Initiative accomplished in a timely fashion. Once done, Drew could claim credit for a full innovation, not an innovation that was two-thirds complete. Their sense of urgency invigorated the other trustees, and the full Board acted in December 1988 to authorize additional funding.

With funding assured, the library began negotiating with a small group of library-automation vendors who could work in the Drew network environment and promise delivery of a system by September 1989. We were searching for a partnership similar to those we had developed with Digital, Bell Atlanticom, Intecom, Octel, and MCI during the installation of the voice-data system. Any new system must add value to the present system and for the library, that meant adding Boolean searching and the potential for other machine-readable databases in the future.

In June 1989 we signed a contract with Data Research Associates, and installed the system over the summer. By the fall, Drew University had a complete network with an online public access catalog that featured Boolean access for all users, along with electronic mail, an online encyclopedia, and many other features. Six years after the introduction of the Computer Initiative, Drew has a system that can serve as a model for other liberal arts institutions in its comprehensiveness, simplicity, and simultaneous concern for cost-containment and innovation.

Those institutions still searching for ways to fund automating a library, or wiring a campus, or delivering sufficient personal computing power to students may want to consider Drew's approach. While the library went without funding in the years when it sought funding for library automation as an isolated activity, the proponents of the network needed the punch of what a fully integrated library system would add to the network in information delivery to sell the network to some faculty and trustees. Coupling the vision with sound budgeting and the need to replace an outdated telephone system was vital. Both the library and the office of the vice-president for technology and planning found that the strongest case for the Knowledge Network rested in its relation not to a given computer or piece of software, but to the vision of value-added information services and delivery.

\title{
NOTIS instruction for the public: Current tools and future needs
}

\author{
By Lynn Westbrook
}

\author{
Coordinator for Reference and Instruction \\ Undergraduate Library, University of Michigan
}

Joining more than 100 other libraries across the country, the University of Michigan recently developed a local version of the NOTIS online catalog. This created a critical need for basic training materials for the public. As part of a User Education Committee Subcommittee on Training for the Public, five librarians created an extensive set of lectures, transparencies, handouts, and exercises that were then distributed to each of the 21 system libraries campuswide. These materials, available on request from LOEX, ${ }^{1}$ are based on a combination of the practical demands faced by busy librarians and basic pedagogical principles. Some portion

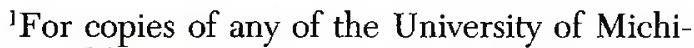
gan's public training material, write to the following address: LOEX, Eastern Michigan University, Ypsilanti MI 48197; (313) 487-0168. of the materials should help meet almost any need with the NOTIS system, or even similar systems.

From a very practical viewpoint, the librarians would be teaching under a wide variety of circumstances. Some would have access to microcomputer centers with a separate workstation for every student, while others would have only an overhead projector in a seminar room. Some would have faculty eager for a full fifty-minute session, while others would be teaching undergraduates at brief walk-in sessions. Many would find reference and even circulation staff expected to brief patrons quickly, while BI librarians would be asked to add a few words onto the end of an already crowded presentation. A few would have access to lab time, but most would not. These widely divergent needs meant that everything must be prepared for fifty-, twenty-, and ten-minute presentations. Each of these presentations had to be prepared both with 